\title{
FUNGSI PRAGMATIS TUTURAN HUMOR MADIHIN BANJAR
}

\author{
Siti Faridah \\ email: sitifaridah@uay.ac.id
}

\author{
Universitas Achmad Yani Banjarmasin
}

\begin{abstract}
The objective of this research is to reveal the pragmatic functions found in speech humor of madihin Banjar by pemadihinan John Tralala. The research uses theoretical and methodological approaches. The researcher uses pragmatics in theoretical approach, while qualitative and descriptive methods in methodological approach. The data were the humorous chunks that contain pragmatic functions in madihin Banjar. The source of data is the humorous discourse in madihin Banjar. The technique of data analysis uses heuristic method by Leech (1983), normative method and interactive technique by Miles and Huberman (1984). The data collection was done by record and note-taking technique. The results show that (1) the pragmatic sub-function of praising, (2) the pragmatic sub-function of saying thank you, (3) the pragmatic sub-function of criticizing, and (4) the pragmatic sub-function of complaining.
\end{abstract}

\section{ABSTRAK}

Penelitian ini bertujuan untuk mengungkap fungsi pragmatis dalam tuturan humor madihin Banjar yang dituturkan oleh pemadihinan John Tralala. Pendekatan yang digunakan dalam penelitian ini adalah pendekatan teoretis dan metodologis. Pendekatan teoretis yang digunakan adalah pendekatan pragmatis, sedangkan pendekatan metodologis yang digunakan adalah pendekatan kualitatif dan pendekatan deskriptif. Data penelitian ini berupa penggalan wacana humor dalam madihin Banjar yang mengandung fungsi pragmatis. Sumber data penelitian ini adalah wacana humor dalam madihin Banjar. Metode dan teknik analisis data digunakan adalah metode heuristik Leech (1983), metode normatif dan teknik interaktif Miles dan Huberman (1984). Pengumpulan data dilakukan dengan metode rekam, simak dan catat. Hasil penelitian ini adalah di dalam tuturan humor madihin Banjar ditemukan (1) subfungsi pragmatis memuji, (2) subfungsi pragmatis mengucapkan terima kasih, (3) subfungsi pragmatis mengkritik dan (4) subfungsi pragmatis mengeluh.

\section{PENDAHULUAN}

\begin{tabular}{ccc}
\multicolumn{2}{c}{ Pandangan yang berkaitan } \\
dengan fungsi
\end{tabular} dikemukakan oleh Rustono (2000: 92). Ia berpendapat bahwa fungsi pragmatis adalah fungsi yang diacu oleh maksud tuturan di dalam pemakaiannya untuk berkomunikasi antarpenutur. Di dalam wacana humor, fungsi itu antara lain adalah menunjang pengungkapan humor. Searle (1969) membedakan tuturan 
pragmatik menjadi lima, yaitu tuturan representatif, direktif, komisif, ekspresif, dan isbati. Tuturan representatif adalah tuturan yang mengikat penuturnya akan kebenaran tuturannya. Istilah lain tuturan representatif adalah tuturan asertif. Di dalam wacana humor ditemukan bahwa tuturan representatif dapat menunjang penciptaan kelucuan.

Tuturan humor merupakan salah satu bentuk tindak tutur yang dapat dijadikan sarana komunikasi. Di dalamnya terdapat informasi, pernyataan rasa senang, marah, kesal atau simpati. Sebagai sarana komunikasi apabila disampaikan dengan tepat, humor dapat berfungsi bermacam-macam Tuturan yang mengandung humor mampu mengurangi ketegangan dan sebagai mediator penyelamat. Sudarmo (1996:1) mengatakan humor merupakan energi budayayang kandungan pengertiaannya amat rumit, maka sangat menarik jika di Indonesia humor diartikan sebagai lucu-lucuan, badut-badutan, guyonan, bahkan sinimisme dan apologisme. Tuturan humor timbul karena ada dua orang atau lebih yang sedang melakukan komunikasi di dalam tuturan tersebut mengandung maksud, tujuan dan fungsi pragmatik tertentu dan menghasilkan beberapa pengaruh pada lingkungan penyimak.

Humor mempunyai jenis yang beragam dan fungsi tertentu. Sudarmo (1996:1) mengklasifikasikannya menjadi empat belas jenis. Jenis-jenis humor tersebut antara lain guyon parikena, satire, sinimisme, kelam, seks, olah estetika, eksperimental dan apologisme. Salah satu fungsi humor adalah sebagai alat kritik yang ampuh. Seringkali orang yang dkritik dengan cara humor, tidak merasakannya sebagai suatu pertentangan. Akan tetapi humor tidak mutlak sebagai obat ampuh menyelesaikan segala permasalahan. Humor bisa menjadi pangkal perselisihan. Fenomena yang ada, seseorang yang mempunyai rasa humor yang rendah bisa menjadi cepat tersinggung dan menangkap sebuah lelucon sebagai ejekan yang menusuk hati. Akan tetapi humor juga dapat membuat orang tertawa apabila mengandung satu atau lebih dari keempat unsur yaitu kejutan yang mengakibatkan rasa malu, ketidakmasukakalan dan yang membesar-besarkan masalah ( Claire dalam Rustono 2000:33-34).

Sebuah kejutan yang dihadirkan seseorang dalam tuturannya terkadang menjadi bahan lelucon. Tuturan yang mengakibatkan rasa malu yang dilontarkan oleh penutur kepada mitra tutur bisa juga menimbulkan lelucon yang mengakibatkan tawa bagi si penutur sendiri atau orang lain. Ketidakmasukakalan tuturan timbul biasanya penutur menuturkan sesuatu yang jauh dari akal sehat. Pada akhirnya mitra tutur bisa juga tidak begitu mempercayai tuturan penutur yang tidak masuk akal itu akibatnya tuturan itu menjadi sebuah humor. Koestler (dalam Rustono 2000:34) menyimpulkan bahwa humor hanyalah satu bentuk komunikasi yang di dalamnya suatu stimulus pada suatu tingkat kompleksitas yang tinggi yang menghasilkan respon yang teramalkan dan tiruan pada tingkat reflek psikologi. Rumusan tersebut didasari oleh pandangan psikologi yang dapat 
dimaknai humor yang merupakan bagian sarana komunikasi yang unik dan multikompleks.

Tuturan ekspresif merupakan tuturan yang menyangkut perasaan dan sikap. Tindak tutur yang dimaksudkan penuturnya agar ujarannya diartikan sebagai evaluasi tentang hal yang disebutkan di dalam tuturan itu. Fraser ( 1978) menyebut tindak tutur ekspresif dengan istilah evaluatif. Tuturan memuji, mengucapkan terima kasih, mengkritik, mengeluh, menyalahkan, mengucapkan selamat, menyanjung termasuk kedalam tuturan ekspresif yang dapat mempengaruhi pikiran orang lain.Tuturan memiliki jenis, fungsi dan kadang-kadang terdapat juga implikatur yang beragam. Begitu pula humor, di dalamnya mengandung jenis tuturan yang beragam dan mempunyai fungsi pragmatis yang beragam pula. Jenis tuturan jika dianalisis berdasarkan kajian pragmatik sangatlah banyak. Salah satunya jenis tuturan ekspresif. Jenis tuturan ini merupakan tuturan yang menyangkut perasaan dan sikap. Tindak tutur yang dimaksudkan penuturnya agar ujarannya diartikan sebagai evaluasi tentang hal yang disebutkan di dalam tuturan itu.

Fraser (1978) menyebut tindak tutur ekspresif dengan istilah evaluatif. Tuturan memuji, mengucapkan terima kasih, mengkritik, mengeluh, menyalahkan, mengucapkan selamat, menyanjung termasuk ke dalam tuturan ekspresif. Sementara itu, fungsi pragmatis tuturan adalah fungsi yang diacu oleh maksud tuturan di dalam pemakaiannya untuk berkomunikasi antar penutur. Misal fungsi pragmatis ekspresif yakni fungsi yang dimaksud tuturan di dalam pemakaiannya untuk berkomunikasi antarpenutur dengan fungsi pragmatis ini, penutur bermaksud menilai atas hal yang dituturkannya, memuji, mengkritik, mengucapkan terimakasih dan mengeluh termasuk substansi pragmatis ekspresif.

Tuturan direktif atau impositif adalah tuturan yang dimaksudkan penuturnya agar mitra tutur melakukan tindakan yang disebutkan dalam tuturannya. Tuturan "Ambilkan ayah kacamata itu," adalah contoh tuturan direktif. Tuturan "Mbak, Mbak, habis belanja apa mau pindahan?" mendukung fungsi pragmatis tertentu. Fungsi pragmatis tuturan itu adalah bertanya.

Tuturan komisif adalah tuturan yang mengikat penuturnya untuk melakukan tindakan yang disebutkan di dalam tuturannya. Sebagaimana halnya tuturan representatif dan direktif tuturan komisif juga terdapat di dalam wacana homor verbal lisan dan dapat berfungsi sebagai penunjang pengungkapan humor. Tuturan "Apa kamu minta tak sulap menjadi monyet... ?" adalah contoh tuturan komisif karena tuturan tersebut mengikat penuturnya untuk melakukan tindakan yang disebutkan di dalam tuturannya, yaitu menyulap (lawan tuturnya) menjadi monyet.

Tuturan ekspresif adalah tuturan yang dimaksudkan penuturnya agar tuturannya diartikan sebagai evaluasi tentang hal yang disebutkan di dalam tuturannya itu. Tuturan, "Wah, jabbatan saya di desa sudah keren, Ketua RT," adalah contoh tuturan ekspresif. Disebut tuturan ekspresif karena di dalam tuturan itu 
penurutnya melakukan evaluasi atas apa yang dituturkannya itu.

Tuturan isbati adalah tuturan yang dimaksudkan penuturnya untuk menciptakan hal (status, keadaan) yang baru. Di dalam wacana humor tuturan isbati berfungsi untuk mendukung penciptaan kelucuan. Contoh tuturan isbati adalah "Oke, karena waktunya sudah habis para peserta ujian diminta untuk meninggalkan ruangan ujian." Disebut demikian karena tuturan itu dimaksudkan penuturnya untuk menciptakan hal (status atau keadaan) baru. Dengan tuturan itu, para peserta ujian yang semula berada di dalam ruangan akan berada di luar ruangaan ujian. Penelitian ini bertujuan untuk mengungkap mengungkap fungsi pragmatis dalam tuturan humor madihin Banjar yang dituturkan oleh pemadihinan John Tralala.

Madihin adalah salah satu jenis sastra lisan yang ada di masyarakat Banjar. Sastra lisan madihin Banjar adalah kesenian tradisional khas Kalimantan Selatan, bersyair atau berpantun diiringi dengan pukulan rebana Hapip (2008:114). Sastra lisan madihin Banjar cukup dikenal di Indonesia setelah dibawakan oleh John Tralala di TVRI pada era 1980an. John Tralala mampu mengangkat sastra lisan madihin Banjar menjadi populer di Indonesia karena pantun dan syair dalam sastra lisan madihin Banjar ini bisa dia kemas dengan bahasa humor. John Tralala sering diundang ke berbagai daerah di Indonesia untuk membawakan sastra lisan madihin Banjar.

Salah satu seniman madihin (pemadihinan) yang mempopulerkan sastra lisan madihin Banjar hingga ke tingkat nasional adalah John Tralala. Dalam perkembangannya, John Tralala dalam bermadihin ditemani oleh anaknya yang bernama Hendra. Mereka membawakan sastra lisan madihin Banjar itu secara berpasangan, John Tralala dan Hendra secara kompak mampu menghibur penonton yang menyaksikan penampilan mereka. Sastra lisan madihin Banjar yang dibawakan oleh John Tralala dan Hendra ini berisi aspek humor yang mengundang tertawa penonton yang hadir. Hal ini sesuai dengan pendapat Sunarti et al (1978:235) yang menyatakan bahwa sastra lisan madihin Banjar berfungsi sebagai hiburan masyarakat.

Syukrani (1994:6) berpendapat bahwa sastra lisan madihin Banjar merupakan karya sastra dipentaskan mempunyai fungsi sebagai penyajian estetis yang dinikmati penonton. Sastra lisan madihin Banjar sering dipentaskan di berbagai acara masyarakat seperti acara keagamaan, acara adat, acara perkawinan, acara menyambut tamu kehormatan, acara hari jadi daerah, acara kenegaraan dan acara-acara meriah lainnya. Kalimat tutur dalam syair dan pantun berbahasa Banjar yang dipentaskan dalam madihin mengandung aspek humor yang tujuannya memberikan hiburan sekaligus nasihat.

Seniman madihin (pemadihinan) adalah orang memainkan sastra lisan madihin Banjar. Dalam penyajian sastra lisan madihin Banjar ada yang dibawakan oleh satu orang pemadihinan (pemain tunggal), bisa juga dibawakan oleh dua orang dan empat orang pemadihinan. Pemain tunggal membawakan syair dan pantunnya harus pandai membawa timber atau 
warna suara yang agak berbeda seperti orator. Pemadihinan harus pandai menarik perhatian penonton dengan humor segar dan mengundang tertawa. Pemadihinan harus benar-benar sanggup memukau penonton dengan irama dinamis pukulan terbangnya (rebana).

Adapun seniman sastra lisan madihin Banjar (pemadihinan) di daerah Kalimantan Selatan selain John Tralala dan Hendra adalah Mat Nyarang dan Masnah pasangan pamadihinan yang paling senior di kota Martapura, Rasyidi dan Rohana di Tanjung, Imberan dan Timah di Amuntai, Nafiah dan Mastura di Kandangan, Khair dan Nurmah di Kandangan, Utuh Syahiban di Banjarmasin, Syahrani di Banjarmasin, dan Sudirman di Banjarbaru. Sastra lisan madihin Banjar ini jika dibawakan oleh dua orang pamadihinan berduet, pemain biasanya beradu atau saling bertanyajawab, saling sindir, saling kalah mengalahkan melalui syair yang dibawakan. Selain itu, sastra lisan madihin Banjar bisa dibawakan oleh empat orang pamadihinan terbagi dua kelompok, masingmasing dua orang pamadihinan, teknik penampilannya sama seperti halnya yang dibawakan oleh dua orang pamadihinan, tetapi kelompok yang satu bisa membantu anggota kelompoknya melawan kelompok yang dihadapinya. Biasanya kelompok ini berpasangan pria dan wanita.

Pemadihinan menuturkan syair dan pantun sastra lisan madihin Banjar dengan lancar secara spontanitas (tanpa konsep maupun hapalan) menggunakan bahasa Banjar dengan muatan nasihat (papadah) dan informasi sesuai perkembangan zaman, situasi dan kondisi yang menghibur penonton. Pemadihinan menyampaikan syair atau pantun madihin berisi nasihat, sindiran, dan aspek humor. Dalam kaitannya dengan aspek humor yang merupakan cabang dari fungsi seni, tuturan pemadihinan dalam membawakan sastra lisan madihin Banjar dapat memberi kesan lucu atau jenaka dan dapat membangkitkan semangat penonton, bahagia dan antusias dalam mengikuti jalannya pertunjukkan sastra lisan madihin. Di samping itu, sastra lisan madihin Banjar juga mengandung unsur pendidikan nasihat dan nilai-nilai kemasyarakatan yang dapat menunjang penyampaian pesanpesan kepada pemerintahan dalam hal pembangunan dan lain-lain.

Dalam setiap pementasan sastra lisan madihin Banjar ini selalu dibatasi oleh aturan-aturan yang sudah baku. Aturan-aturan itu harus dipatuhi oleh para seniman madihin (pemadihinan). Setiap pementasan Sastra lisan madihin Banjar terlihat adanya struktur yang sudah baku yaitu terdiri dari pembukaan, memasang tabi, menyampaikan isi dan penutup. Selaras dengan hal ini, Thabah (1999:9) berpendapat bahwa dalam penyampaian syair dan pantun sastra lisan madihin Banjar yang dibawakan pemadihinan sudah ada struktur penyampaiannya yang baku, yaitu terdiri atas empat langkah:

a. pembukaan, adalah melagukan sampiran sebuah pantun yang diawali pukulan terbang yang disebut pukulan membuka. Sampiran pantun ini biasanya akan memberikan informasi tema apa yang akan dibawakan 
dalam penyampaian pantun madihin;

b. memasang tabi, adalah membawakan syair-syair atau pantun yang isinya menghormati penonton, dan memohon maaf jika terdapat kekeliruan dalam penyampaian;

c. menyampaikan isi (manguran), adalah menyampaikan syairsyair atau pantun yang selalu selaras dengan tema penyampaian atau sesuai dengan permintaan pihak penyelenggara. Sebelum sampiran pantun dipembukaan harus disampaikan isinya terlebih dahulu (mamacah bunga); dan

d. penutup, adalah menyampaikan simpulan dari apa yang baru saja disampaikan sambil menghormati penonton, dan mohon pamit, serta ditutup dengan pantun- pantun serta lagu-lagu.

Sastra lisan madihin Banjar struktur penyampaiannya tampak sebagai berikut.

Pembukaan

Asalammualaikum ulun mangawalinya

'Asalammualaikum

mengawalinya'

saya

Sabagai salam untuk pian samuanya

'Sebagai salam untuk hadirin semuanya'

Bukanlah ulun pamadihinan aslinya 'Bukanlah saya pamadihinan aslinya' Mun ulun salah, muhun pian mamakluminya

'Kalau saya salah, mohon hadirin memakluminya'

96 | Jurnal Kredo Vol. 1 No. 1 Oktober 2017
Madihin ulun ini, madihin asli

'Madihin saya ini, madihin asli'

Amun kada parcaya, silahakan mandangari

'Kalau tidak percaya, silahkan mendengarkan'

Kini ulun mambawaakan ulahan sandiri

'Kini saya membawakan buatan sendiri'

Dangan judul babakti lawan kuitan laki

'Dengan judul berbakti dengan orang tua laki-laki'

Mamasang Tabi:

Tarima kasih ulun ucapakan

'Terima kasih saya ucapkan'

Atas sambutan sampiyan samuaan

'Atas sambutan hadirin semuanya'

Amun ulun salah, jangan ditatawaakan

'Kalau saya salah, jangan ditertawakan'

Maklumlah ulun hanyar cacobaan

'Maklumlah saya baru coba-coba'

Salamat datang hadirin nang tarhormat

'Selamat datang hadirin yang terhormat'

Kuucap salam supaya samua salamat

'Kuucap salam supaya semua selamat'

Tasanyum dulu itu sabagai syarat

'Tersenyum dulu itu sebagai syarat'

Supaya salamat dunia lawan ahirat

'Supaya selamat dunia dan akhirat'

Baik nang di balakang atawa di hadapan 'Baik yang di belakang atau di depan'

Baik nang bujang atawa baranakan 'baik yang bujang atau yang sudah mempunyai anak'

Baik nang baingusan atawa baliuran

'baik yang beringusan atau yang berliuran'

Baik nang badirian atawa nang badudukan duduk'

$$
\text { 'baik yang berdiri atau yang }
$$


Manguran (penyampaian ide)

Ayah: Oh anakku si belahan hati

'Oh anakku si belahan hati'

Bagaimana kalau abahmu babini lagi?

'Bagaimana kalau ayahmu beristri lagi?'

Apakah ikam akan manyatujui?

'Apakah kamu akan menyetujui?'

Sarta akan mamiliki uma tiri?

'Serta akan memiliki ibu tiri?'

anak: Tantu saja, ulun akan mangadili mengadili'

'Tentu saja, saya akan

Kapapurunan pian sabagai saurang laki

'Tega sekali ayah sebagai seorang suami'

Kalau parlu, abah akan kutinggali

'Kalau perlu, ayah akan saya jauhi'

Karna calon abah ulun ambil bini

'Karena calon istri ayah saya ambil sebagai istri'

ayah: Oh anakku ikam wani sakali

'Oh anakku kamu berani

sekali'

Kada takutankah ikam di ahirat nanti

'Tidak takutkah kamu di akhirat nanti'

Mun aku tahu kalakuan ikam bagini

'Kalau saya tahu kelakuan kamu begini'

Sudah dari dulu ikam kusariki

'Sudah dari dulu kamu saya marahi'

anak: Ya, abahku, pian sarik sakali

'Ya, ayah marah sekali'
Bukan maksud ulun handak malawani

'Bukan maksud saya hendak menentang'

Karna tapaksa ulun manjadi wani

'Karena terpaksa saya menjadi berani'

Muhun dimaapakan dan juga diampuni

'Mohon dimaafkan dan juga diampuni'

anak: Oh abahku, pian sangar sakali

'Oh ayahku, sangar sekali'

Bila sarik mata pian mencangangi

'Bila marah mata ayah cengang sekali'

Ulun kada wani bila pian manyariki

'Saya tidak berani bila ayah memarahi'

Muntung babunyi, batis tangan pun baraksi

'Mulut berbunyi, kaki tangan pun beraksi'

ayah: Kalau memang zaman sudah baganti

berganti'

'Kalau memang zaman sudah

Handak rasanya aku babini lagi

'Ingin rasanya saya beristri lagi'

Handak nang langkar atawa nang sudah balaki

'mau yang cantik atau yang pernah bersuami'

Cukup pangalamannya, kada usah dilajari

'Cukup pengalamannya, tidak usah diajari’

\section{Penutup}

Di satop dahulu ulun bamadihinan

'Di stop dahulu saya bermain madihin'

Ngalu kapala bapandir kada karuan 
'Pusing kepala berbicara tidak keruan'

Handak rasanya ulun bukah saurangan

'ingin rasanya saya lari sendirian'

Biar badiam pian batatawaan

'Biar berdiam anda/hadirin tertawa'

Tarima kasih ulun haturakan

'Terima kasih saya sampaikan'

Atas parhatian sampai di pahujungan

'Atas perhatian sampai di akhir'

Cukup sakian ulun mamadahakan

'Cukup sekian saya memberitahukan'

Agar jangan salah dalam manarapakan

'Agar jangan salah dalam menerapkan'

Sadang bamandak sadang pula batahan

'Cukup berhenti cukup pula berhenti'

Karna ulun sudah kauyuhan

'Karena saya sudah sangat lelah)'

Limbui bapaluhan, muntung sudah baliuran

'Bersimbah peluh, mulut sudah keluar liur'

Kapada hadirin mohon batapuk tangan

'Kepada hadirin mohon bertepuk tangan'

(Dikutip dari Ghany 1999:9)

Ciri khas sastra lisan madihin Banjar menggunakan bahasa daerah Banjarmasin. Namun, dalam pementasan pantun dan syair oleh pemadinan ini biasanya disesuaikan dengan penonton yang hadir. Kalau yang hadir banyak orang dari etnik Banjar, pamadihinan menggunakan bahasa Banjar dalam membawakan sastra lisan madihin. Akan tetapi, kalau yang hadir berasal dari berbagai suku bangsa di Indonesia, pamadihinan menggunakan bahasa Indonesia. Kesenian tradisional madihin Banjar ini disajikan oleh pamadihinan yang melagukan pantun dan syair sambil memukul alat pukul terbang (rebana).

Keberadaan sastra lisan madihin Banjar terjadi penurunan intensitas, dahulu hampir semua acara dipentaskan kesenian madihin Banjar, sekarang hanya dalam acara pengantin, pergelaran panggung hiburan yang sifatnya pencarian dana, dan kegiatan-kegiatan pemerintahan. Perkembangan sastra lisan madihin Banjar sekarang sebagaimana dikatakan Sastrowardoyo et al (1983:5) tidak sepesat dulu. Hal itu karena longgarnya ikatan tradisi masyarakat dan sikap ketidakpedulian masyarakat Banjar terutama generasi muda sekarang dalam penggunaan sastra lisan itu dalam kehidupan sehari-hari.

Selanjutnya, Mahmud (2000:1) menambahkan bahwa ketidakpedulian itu berkaitan dengan kurangnya pengetahuan masyarakat tentang fungsi dan peranan sastra lisan dalam masyarakatnya. Kenyataan lain, disebabkan oleh kurangnya sastra lisan yang telah didokumentasi dan dicetak. Sastra lisan Banjar khususnya madihin yang belum dihimpun dan disusun menjadi dokumen lengkap dikuatirkan akan punah. Oleh karena itu, sastra lisan madihin Banjar harus segera diinventarisasi, diteliti, dan dianalisis serta dibukukan agar dapat digunakan sebagai salah satu pengetahuan tentang sastra lisan daerah Banjar.

Salah satu sastra lisan Banjar pada saat ini yang hampir punah penerusnya adalah kesenian tradisional madihin yang berasal dari Banjar Kalimantan Selatan. Kesenian daerah merupakan ciri dan identitas 
suatu daerah. Sumber nilai-nilai dan rambu-rambu masyarakat. Sastra lisan perlu dilestarikan dan dipertahankan agar tidak punah. Hal ini penting karena jika produk sastra lisan di suatu daerah punah, hakikatnya kebudayaan lisan itu sendiri telah ikut punah. Jika produk sastra di suatu daerah punah, daerah tersebut telah kehilangan rekaman penggunaan bahasa lisan yang telah diwariskan oleh para pendahulunya. Jika sastra lisan punah, sebagian dari kebudayaan suatu daerah pun punah, dan akan berimplikasi terhadap eksistensi kebudayaan nasional. Penelitian tentang sastra lisan madihin Banjar ini penting dilakukan karena untuk melestarikan agar identitas daerah Banjar tidak hilang.

Faktor lain yang menyebabkan makin berkurangnya minat masyarakat terhadap berbagai bentuk sastra lisan madihin Banjar adalah faktor makin berkurangnya seniman tradisional yang mengolah karya seni madihin Banjar. Bahkan, karya seni itu makin tertinggal oleh arus globalisasi dengan masuknya hiburan seni modern yang terus berkembang pesat sesuai dengan tuntutan zaman. Hal ini, makin menguatkan minat peneliti untuk meneliti secara mendalam tentang sastra lisan madihin Banjar ini agar tidak punah. Perkembangan zaman cenderung selalu mengarah pada modernisasi yang selalu identik dengan budaya Barat. Hal ini dapat dilihat dari kebudayaan musik pop yang memiliki tingkat popularitas yang lebih tinggi bagi anak muda jika dibandingkan dengan kesenian tradisional yang kebanyakan hanya diminati oleh orang-orang tua. Bila sastra lisan madihin Banjar ini tidak lagi populer dan minat terhadapnya makin kurang, dapat dipastikan warisan budaya Banjar yang sangat berharga ini dapat hilang ditelan perkembangan zaman. Oleh sebab itu, diperlukan pendokumentasian dalam berbagai bentuk agar karya seperti ini dapat terus terjaga kelestariannya, seperti buku, rekaman, dan penelitian.

Sastra lisan madihin Banjar mempunyai nilai-nilai luhur yang perlu dikembangkan dan dimanfaatkan dalam hubungan usaha pembinaan serta penciptaan sastra lisan daerah. Pelestarian sastra lisan ini dirasa sangat penting, karena sastra lisan hanya tersimpan dalam ingatan orang tua atau sesepuh yang makin berkurang. Sastra lisan madihin Banjar ini juga berfungsi sebagai penunjang perkembangan bahasa lisan dan sebagai pengungkap pikiran serta sikap dan nilai-nilai kebudayaan masyarakat pendukungnya. Sastra lisan juga merupakan budaya yang menjadikan bahasa sebagai media, dan erat ikatannya dengan kemajuan bahasa masyarakat pendukungnya, sehingga perlu adanya penyelamatan agar tidak hilang, dan generasi ke generasi dapat mengenal serta menikmati kekayaan budaya lisan tersebut.

Pada dasarnya fungsi sastra lisan madihin Banjar adalah sebagai hiburan tetapi di dalamnya terdapat pesan-pesan moral, media informasi, sosialisasi program pemerintah, media pendidikan, dan media hiburan untuk pencarian dana. Sastra lisan madihin Banjar selain untuk menghibur juga berfungsi sebagai sarana untuk mengkritik pemerintah, kritik jenaka, media informasi, sosialisasi program pemerintah, media pendidikan, dan pengarahan agama, karena sastra lisan madihin 
Banjar ini identik dengan syair atau pantun dan lelucon (humor) agar orang itu tidak mudah tersinggung, dan berfungsi juga mengkritik pemerintah dalam hal yang bersifat tidak selaras dengan pembangunan.

Sastra lisan madihin Banjar pada awalnya berfungsi menghibur rajaraja atau pejabat. Isi syair dan pantun berisi pujian-pujian sang raja dan pejabat istana. Sebagai hiburan bagi rakyat pada acara tertentu seperti mengisi hiburan sehabis panen, perkawinan, sunatan dan lain-lain. Dalam perkembangan berikutnya fungsi sastra lisan madihin Banjar adalah sebagai sarana hiburan bagi masyarakat pengisi acara tertentu seperti, perkawinan, khitanan, peringatan hari-hari besar dan Nasional, 17 Agustsus, dan lain-lain. Selain itu, sastra lisan madihin Banjar ini berfungsi sebagai sarana penyampaian pesan kepada masyarakat, seperti penyuluhan pembangunan, kesehatan, dan sebagai alat kontrol sosial.

Alasan dipilihnya tuturan humor madihin Banjar ini sebagai objek penelitian dalam penelitian ini karena dalam tuturan humor tersebut banyak terdapat tuturan ekspresif yang beragam dan berfungsi sebagai alat kritik yang menampilkan sketsa sosial yang merekam dan membidik kenyataan kehidupan dengan perspektif kejenakaan yang menyisakan berbagai keganjilan yang mengusik lahirnya celetukan atau guyonan.oleh karena itu dalam tuturan ini memungkinkan untuk dianalisis.

Di dalam penelitian ini hanya dibahas hasil penelitian fungsi pragmatis subtuturan humor eskpresif. Dengan demikian subtuturan humor yang lain, yaitu representatif, direktif, komisif, dan isbati tidak dibahas di dalam artikel ini karena keterbatasan ruang.

\section{METODE PENELITIAN}

Dalam penelitian ini digunakan pendekatan teoretis (pragmatis) dan metodologis. Desain penelitian ini adalah desain penelitian kualitatif. Data penelitian ini berupa penggalan wacana humor dalam madihin Banjar. Sumber data penelitian ini adalah wacana humor sastra lisan madihin Banjar karya John Tralala. Madihin ini terdiri atas sebelas judul, yaitu (1) "Lawak Lucu Ful Madihin Banjar John Tralala Live Binuang", (2) "Madihin Cewek Cantik Masih Muda", (3) "Tampil di Inbox", (4) "Lawak dan Madihin John Tralala Part 1", (5) "Madihin Penganugerahan KPID Award", (6) "Madihin Banjar John Tralala At Taman Balairungsari", (7) "Madihin John Tralala di Milad Kerajaan Banjar ke-508", (8) "Palui Banasib Sial", (9) "Madihin John Tralala Kedatangan SBY", (10) "Madihin di Pangelaran Seni Budaya Anti Narkoba", dan (11) "Madihin Anang Syahrani, S.Ag di IAIN Antasari Banjarmasin". Penelitian ini dilakukan pada madihin judul yang pertama, yaitu "Lawak Lucu, Full Madihin Banjar John Tralala Live Binuang" yang terdiri atas 24 bait itu.Naskah yang menjadi kajian merupakan hasil transkripsi dari rekaman madihin Banjar karya John Tralala dari sebelas judul.

Pengumpulan data dilakukan dengan membaca trankripsi madihin Banjar itu secara berulang-ulang sehingga ditemukan data yang 
relevan. Teknik pengumpulan data penelitian ini adalah rekam, simak dan catat. Instrumen penelitiannya adalah peneliti sendiri. Proses pencatatan (recording) dilakukan dengan kartu data. Satuan data dalam penelitian ini berupa kata, frasa, baris, dan bait. Metode dan Teknik analisis data yang digunakan adalah metode heuristik dan metode normatif. Selain itu, dalam penelitian ini digunakan teknik analisis data model interaktif (interactive analysis models). Data yang terkumpul diberi kode (coding), diklasifikasi berdasarkan pokok kajian dan dimaknai berdasarkan referensi yang menjadi rujukan. Simpulan diambil secara induktif.

Keabsahan penelitian diuji dengan menggunakan validitas semantik dan intrareter. Validitas semantik dilakukan dengan cara memaknai bagian-bagian struktur kalimat (baris) atau wacana yang ditampilkan. Itrareter dilakukan dengan cara membaca puisi itu secara cermat dan berulang-ulang sehingga ditemukan data yang benarbenar sesuai dengan pokok kajian. Kredibilitas penafsiran data penelitian dilakukan dengan diskusi dengan teman sejawat (peer discussin) dan tim promotor atau dosen pempimbing. Berdasarkan berbagai masukan tersebut, laporan penelitian dan artikel disusun dan disempurnakan.

\section{HASIL DAN PEMBAHASAN}

Fungsi pragmatis eskpresif adalah fungsi yang diacu oleh maksud tuturan di dalam pemakaiannya untuk menyatakan penilaian. Dengan fungsi pragmatis ini penutur menyatakan penilaian atas hal yang dituturkannya. Termasuk ke dalam fungsi pragmatis ini adalah empat subfungssi pragmatis, yaitu memuji, mengucapkan terima kasih, mengkritik, dan mengeluh. Sesuai dengan namanya, yaitu ekspresif, tuturan yang menyatakan keempat subfungsi pragmatis ekspresif itu berdasarkan hasil kegiatan menilai penuturnya atas hal-hal yang diketahui oleh penuturnya.

Di dalam wacana humor madihin John Tralala terdapat sejumlah tuturan yang berfungsi pragmatis ekspresif dengan keempat subfungsi pragmatis ekspresif dengan keempat subfungsi pragmatisnya, yaitu memuji, mengucapkan terima kasih, mengkritik, dan mengeluh. Keempat tuturan itu, selain menyatakan fungsi pragmatis atau berfungsi pragmatis eskpresif tertentu, juga berfungsi sebagai penunjang pengungkapan humor.

Penggalan wacana humor madihin John Tralala berikut terdapat di dalamnya tuturan yang menyatakan subfungsi pragmatis memuji.

(1) KONTEKS : JOHN TRALALA MEMUJI PENAMPILAN ANANG YANG DIKATAKAN ASYIK SEHINGGA PENONTOH WANITA BANYAK YANG SUKA. JOHN TRALALA: Penampilan Anang malam ini memang asyik

Banyak penonton ini yang jatuh hati Khususnya para cewek Mereka semua senang di dalam hati Yang sebelah kiri mereka berkata Anang ganteng sekali 
Yang sebelah kanan Anang ini seperti artis di televisi"

Di dalam penggalan wacana humor madihin John Tralala (bait 4) itu terdapat tuturan John Tralala yang memiliki fungsi pragmatis memuji. Hal itu terjadi karena tuturan Tralala tersebut mengacu kepada maksud tuturan yang memang menyatakan sesuatu pujian, yaitu memuji kegantengan Anang, rekan pemadihin. Konteks tuturan yang mendukung tuturan itu adalah Anang mendapatkan sanjungan atau pujian dari penonton, khususnya para wanita.

Tuturan Tralala tersebut juga berfungsi menungjang pengungkapan humor. Fungsin itu terealisasi karena adanya implikatur yang terselubung di dalam tuturan ituakibat pelanggaran prinsip kerja sama bidal kualitas. Implikatur itu adalah penilaian yang berlebihan, yaitu Anang dikatakan 'seperti artis di televisi'. Hal itu menjadikan penonton tertawa. Kelucuan yang ditunjang oleh implikatur itu juga didukung oleh ekspresi Tralala yang membombong dan ekspresi Anang yang menanggapinya dengan sewot.

Humor yang ditunjang oleh tuturan Tralala itu bertipe humor verbal lisan karena diekspresi dengan kata-kata atau bahasa dan secara lisan. Sejalan dengan pembedaan humor atas motivasinya, yaitu menjadi komik, humor, dan wit, penggalan wacana (1) itu tergolong wacana humor karena kandungan motivasinya yaitu cemoohan Tralala kepada rekan mainnya, Anang. Dilihat dati tekniknya humor ini termasuk humor ridicule karena mengandung maksud mengejek atau mencemooh.
Di dalam penggalan wacana humor madihin John Tralala berikut terdapat tuturan yang menyatakan subfungsi pragmatis mengucapkan terima kasih.

(2) KONTEKS : DI HADAPAN PARA PENONTON JOHN TRALALA

\section{MENGUCAPKAN TERIMAKASIH KEPADA MUH HATTA KARENA TELAH MENGUNDANG MADIHIN UNTUK MENGHIBUR MASYARAKAT KALIMANTAN SELATAN.}

JOHN TRALALA: Bapak dan ibu yang saya muliakan

Terima kasih kami ucapkan

Kepada pak Haji Muh Hatta

Atau pak Haji Ciyut yang telah mengundang

Mengundang kami untuk menghibur masyarakat Kecamatan Binuang

Berarti beliau turut melestarikan

Budaya Daerah Kalimantan Selatan

Kita semua mendoakan'.

Tuturan yang menyatakan subfungsi pragmatis mengucapkan terima kasih di dalam penggalan humor verbal lisan madihin John Tralala (2) itu adalah tuturan John Tralala kepada Haji Muh Hatta. Tuturan itu mengacu kepada maksud tuturan untuk mengucapkan terima kasih atas kesempatan yang diberikan Haji Muh Hatta kepada kelompok madihin John Tralala untuk menghibur mayarakat Kalimantan Selatan. Konteks tuturan yang mendukung tuturan itu adalah 
bahwa Tralala mengucapkan terima kasih kepada Haji Muh Hatta yang telah mengundang kelompoknya.

Fungsi sebagai penunjang humor juga diperankan oleh tuturan itu. Kelucuan itu ditunjang oleh adanya implikatur yang dikandung olen tuturan itu yang timbul sebagai akibat terjadinya pelanggaran prinsip kerja sama bidal kualitas. Implikatur tuturan Tralala itu adalah senang dan mengundang respon tertawa penikmat karena hal itu berarti menunjukkan adanya kesan pelecehan atau setidak-tidaknya merendahkan. Untuk menghormatinya, Muh Hatta dipanggil Haji Muh Hatta. Akan tetapi dia juga disapa dengan kata sapaan Haji Ciyut untuk mendatangkan gelak tawa penonton.

Karena dinyatakan dengan katakata dan secara lisan, humor yang ditunjuk oleh implikatur tuturan Tralala itu bertipe humor verbal lisan. Penggalan wacana (2) itu tergolong tipe humor karena kandungan motivasinya. Atas dasar topiknya, penggalan wacana itu bertipe humor tuan. Sementara itu, berdasarkan tekniknua, humor verbal lisan itu bertipe ridicule karena terdapat di dalamnya maksud tertentu.

Penggalan wacana humor madihin John Tralala berikut terdapat di dalamnya tuturan yang menyatakan subfungsi pragmatis mengkritik.
(3) KONTEKS : DI DEPAN PENONTON JOHN TRALALA

\author{
MEMPERKENALKAN \\ ANAKNYA YANG BERNAMA \\ SAID YANG BELUM BANYAK \\ PENGALAMAN.
}

JOHN TRALALA : Malam ini saya akan memperkenalkan
Anak saya yang bernama Said paling tampan

Bagaikan burung yang terdapat di dalam hutan

Dengan cewek belum banyak pengalaman

Seperti burung Tinjau di dalam sangkar

Tidak berkicau dan hanya diam'.

Tuturan John Tralala pada penggalan wacana humor madihin John Tralala (3) itu adalah tuturan yang memiliki fungsi pragmatis mengkritik. Mengkritik adalah memberikan pertimbangan atas baik dan buruk pada diri seseorang atau sebuah karya. Alasannya adalah bahwa tuturan Tralala tersebut mengacu kepada maksud tuturan yang memang dimaksudkan untuk mengkritik atas diri Said. Konteks tuturan yang mendukung tuturan itu adalah perilaku John Tralala memperkenalkan anaknya, Said, di depan penonton.

Tuturan Tralala itu itu juga berfngsi menunjang pengungkapan humor. Fungsi itu terealisasi karena adanya implokatur yang tersirat di dalam tuturan itu yang timbul akibat pelanggaran prinsip kerja sama bidal kualitas. Implikatur tuturan Tralala 
itu adalah 'rasa malu' karena kritikannya. Dikatakan olehnya bahwa Said adalah seorang anak yang paling tampan (kelebihan) akan tetapi dikatakannya pula bahwa Said juga seorang laki-laki yang belum banyak pengalaman (kekurangan).

Tipe humor yang ditunjang oleh tuturan Tralala itu adalah tipe humor verbal lisan karena dinyatakan dengan kata-kata dan secara lisan. Berdasarkan atas motivasinya menjadi komik, humor, dan wit, penggalan wacana (3) itu termasuk tipe humor karena terdapat di dalamnya motivasi, yaitu mencemooh. Berdasarkan topiknya, penggalan wacana itu adalah tipe humor tingkah laku manusia. Dari segi tekniknya, humor verbal lisan itu bertipe ricidule karena mengandung maksud mengejek atau mencemooh.

Di dalam penggalan wacana humor madihin John Tralala berikut terdapat tuturan yang menyatakan subfungsi pragmatis mengeluh.

(4) KONTEKS TRALALA AKAN JOHN MENGELUH KEADAAN ZAMAN INI KESENJANGAN SOSIAL SEMAKIN MENJADI JADI.

JOHN TRALALA: Coba kita lihat di zaman sekarang ini Kita makin sulit masalah ekonomi Kesenjangan sosial sekarang sering terjadi Coba kita lihat di zaman sekarang ini Kalau orang kaya makanannya daging ayam dan daging Sapi Kalau orang miskin makanannya ikan asin Sampai berdarah-darah tertusuk gusi

Tuturan yang menyatakan subfungsi pragmatis mengeluh di 104 | Jurnal Kredo Vol. 1 No. 1 Oktober 2017 dalam penggalan wacana humor madihin John Tralala (4) itu adalah tuturan John Tralala karena mengacu kepada maksud tuturan untuk mengeluh, yaitu mengeluh karena kehidupan ekonomi yang semakin sulit. Ekspresi mengeluh itu dinyatakannya kepada penonton atau hadirin dalam sebuah pertunjukan seni madihin. Konteks tuturan yang mendukung tuturan itu adalah John Tralala mengeluh berkenaan dengan kehidupan ekonomiyang semakin selit itu.

Fungsi penunjang humor juga diperankan oleh tuturan Tralala itu. Humor itu semakin lucu karena adanya implikatur yang dikandung oleh tuturan itu, yaitu kesal akibat pelanggaran prisip kerja sama bidal cara. Implikatur itu mengundang respon tertawa penonton, karena dituturkan bahwa orang miskin (yang) makanannya ikan asin sampai berdarah-darah tertusuk gusi akibat makan ikan asin itu. Dapat dikatakan bahwa tuturan yang memerankan subfungsi pragmatis mengeluh dan yang berimplikatur dengan dukungan ekspresir penuturnya di dalam wacana humor berfungsi menungjang pengungkapan kelucuan.

Karena dinyatakan dengan katakata atau bahasa dan secara lisan, humor yang ditunjang oleh implikatur yang dikandung tuturan Tralala itu adalah tipe humor verbal lisan. Atas dasar ada tidaknya motivasi, penggalan wacana (4) itu tergolong tipe humor karena kandungan motivasinya. Berdasarkan topiknya, penggalan wacana itu, berupa tipe humor tingkah laku manusia. Sementara itu, dari segi tekniknya, humor verbal lisan itu bertipe 'ridicule' karena 
mengandung maksud, yaitu mengharapkan perhatian.

\section{SIMPULAN}

Fungsi pragmatis tuturan humor madihin Banjar karya John Tralala dibedakan menjadi representatif, direktif, komisif, ekspresif, dan isbati. Tuturan ekspresif terdiri atas empat subfungsi yaitu memuji, mengucapkan terima kasih, mengkritik, dan mengeluh.

\section{DAFTAR PUSTAKA}

Fraser, Bruce. 1978. "Acquiring Social Competence in a Second Language" dalam

REALC Journal Volume No. 2 Desember 1978.

Leech, Geoffrey.,1986, The Principles of Pragmatics, London : Longman Group Limited.

Mahmud, Saifuddin. (2000). Struktur Sastra Lisan Simeulue. Jakarta: Pusat Bahasa.

Rustono. 2000. Implikatur Tuturan Humor. Semarang: IKIP Semarang Press.

Searle, J.R. 1969. Speech Act. Cambridge; Cambridge University Press.

Syukrani, Maswan. 1994. Deskripsi Madihin. Banjarmasin: Kanwil Departemen.

Thabah. 1999. Madihin. Tabloid Wanyi, Edisi 11/Tahun I, 1 September, Hal. 9.

Wijana, Dewa Putu. 1996. Dasar-dasar Pragmatik. Yogyakarta: Andi Offset. 